\title{
Variáveis Morfogênicas e Estruturais de Azevém Anual (Lolium multiflorum Lam.) Ma- nejado em Diferentes Alturas
}

\author{
Laíse da Silveira Pontes ${ }^{1}$, Carlos Nabinger ${ }^{2}$, Paulo César de Faccio Carvalho², \\ Júlio Kuhn da Trindade ${ }^{3}$, Daniel Portella Montardo ${ }^{4}$, Rogério Jaworski dos Santos ${ }^{3}$
}

RESUMO - Variáveis morfogênicas e estruturais foram quantificadas a partir da técnica de "perfilhos marcados" no período de agosto a outubro de 1999 numa pastagem de azevém anual, mantida em quatro diferentes alturas $(5,10,15$ e $20 \mathrm{~cm})$ através de lotação contínua em carga variável com ovinos. O delineamento experimental foi o de blocos completos casualizados com três repetições. Utilizaram-se 50 perfilhos marcados por unidade experimental, distribuídos ao longo de transectas. As observações foram efetuadas em dois períodos: no primeiro, da entrada dos animais até a obtenção das alturas pretendidas, não se observaram diferenças entre os tratamentos. No segundo (fase de estabilização das alturas pretendidas), a taxa de elongação foliar, o comprimento da lâmina verde total por perfilho e o tamanho das folhas apresentaram resposta positiva frente a maiores alturas de manejo, enquanto o tempo de elongação da lâmina foliar diminui com a altura. As variáveis taxa de surgimento de folhas, tempo de vida das folhas, densidade populacional de perfilhos e número de folhas vivas por perfilho não foram afetadas pelos tratamentos.

Palavras-chave: perfilhos marcados, altura, azevém, pastejo, ovinos

\section{Morphogenetic and Structural Traits of Ryegrass (Lolium multiflorum Lam.) Managed under Different Sward Heights}

\begin{abstract}
Morphogenetic and structural variables were obtained from measurements performed on marked tillers and were quantified during August to October 1999 in a ryegrass pasture grazed by sheep under continuous stocking and variable stocking rate in order to maintain the sward at four different heights $(5,10,15$ and $20 \mathrm{~cm})$. The experimental design was a randomized complete block with three replicates. Fifty marked tillers per experimental unit were assessed and distributed along transects lines. Sward measurements were performed in two periods: the first one, from the start of grazing until the point where the intended grazing heights were established, with no differences among treatments. In the second (after achieving the intended grazing heights), leaf elongation rate, total green leaf lamina length per tiller and leaf size showed a positive response to increasing sward heights, while the time to leaf lamina elongation decreased. The variables leaf appearance rate and leaf life span, tiller population density and number of live leaves per tiller were not affected by treatments.
\end{abstract}

Key Words: marked tillers, sward height, ryegrass, grazing, sheep

\section{Introdução}

Segundo Lemaire \& Chapman (1996), a morfogênese pode ser definida como a dinâmica de geração e expansão da forma da planta no espaço. Embora seja geneticamente programada essa dinâmica pode ser fortemente influenciada por variáveis ambientais tais como temperatura, disponibilidade hídrica e de nutrientes.

As taxas de elongação foliar (TEF), de surgimento de folhas (TSF) e tempo de vida das folhas (TVF) são as variáveis morfogênicas que determinam as principais características estruturais da pastagem, a saber: tamanho de folha, densidade populacional de perfilhos e número de folhas vivas por perfilho. Essas variáveis, em conjunto, definem o índice de área foliar (IAF) da pastagem e sua capacidade de interceptar e fornecer energia para as funções de crescimento, absorção de água e nutrientes pelas raízes (Davies, 1993). A dinâmica do processo de morfogênese é fortemente afetada pelo manejo da pastagem via efeito sobre o seu IAF. Um exemplo é o processo de remobilização de $\mathrm{N}$ das folhas em senescência para a produção de novos tecidos foliares, influenciando diretamente a TEF devido ao maior acúmulo desse nutriente na zona de divisão celular (Lemaire \& Agnusdei, 1999).

Como diferentes alturas de manejo proporcionam diferenças na estrutura da pastagem e, conseqüentemente, na morfogênese da planta, uma vez que alteram a dinâmica do processo de desfolhação efetuado

\footnotetext{
1 MSc. em Zootecnia - Departamento de Plantas Forrageiras e Agrometeorologia - UFRGS, Porto Alegre, RS. E.mail: Ispontes@zipmail.com.br 2 Professor Adjunto do Departamento de Plantas Forrageiras e Agrometeorologia - UFRGS. E.mail: nabinger@ufrgs.br; paulocfc@ufrgs.br

3 Bolsista de Iniciação Científica, Faculdade de Agronomia - UFRGS. E.mail: jaworski@yahoo.com.br; catrindade@ig.com.br

4 Estudante de Doutorado em Zootecnia - UFRGS, Porto Alegre - RS. E.mail: dmtrevo@terra.com.br
} 
pelo animal, objetiva-se, neste trabalho, conhecer o comportamento dessas variáveis morfogênicas e estruturais em relação aos diferentes níveis de disponibilidade de forragem estabelecidos por quatro alturas de manejo do pastejo em pastos de azevém anual (Lolium multiflorum Lam.).

\section{Material e Métodos}

O experimento foi conduzido na Estação Experimental Agronômica da Universidade Federal do Rio Grande do Sul (EEA - UFRGS). A EEA localiza-se a $30^{\circ} 05^{\prime} \mathrm{S}$ e $51^{\circ} 40^{\prime} \mathrm{W}$, com altitude de $46 \mathrm{~m}$ do nível do mar. O clima, segundo a classificação de Köppen, é do tipo Cfa (subtropical úmido com verão quente). Apresenta temperatura média mensal que varia de $14,2^{\circ} \mathrm{C}$ a $24,9^{\circ} \mathrm{C}$ e precipitação média em torno de $1440 \mathrm{~mm}$ anuais. O solo está classificado como um PLINTOSSOLO ARGILÚVICO Distrófico (FTd), segundo o Sistema Brasileiro de Classificação de Solos (EMBRAPA, 1999).

O experimento foi conduzido numa área de 4,98 ha, dividida em 12 piquetes. A pastagem foi semeada em plantio direto com renovadora de pastagem em 28/05/99 na densidade de $40 \mathrm{~kg}$ de sementes de azevém anual por hectare e adubada com $20 \mathrm{~kg}$ de N, $70 \mathrm{~kg}$ de $\mathrm{P}_{2} \mathrm{O}_{5}$ e $15 \mathrm{~kg}$ de $\mathrm{K}_{2} \mathrm{O} / \mathrm{ha}$ (uréia, superfosfato triplo e $\mathrm{KCl}$ ) na base. Posteriormente foram feitas duas aplicações de $\mathrm{N}$ em cobertura, sendo aplicados $138 \mathrm{~kg}$ de N/ha no dia 30/06/1999 e 68 $\mathrm{kg}$ de N/ha no dia 10/09/1999 na forma de uréia. Os tratamentos consistiram de quatro alturas de manejo da pastagem, quais sejam: $5,10,15$ e 20 $\mathrm{cm}$. O delineamento experimental utilizado foi o de blocos completos casualizados com três repetições. Os animais experimentais foram cordeiros cruzados da raça Texel (CG1 e CG3) e animais Ile de France, todos inteiros com idade média aproximada de um ano e apresentando um peso individual médio inicial de $36,1 \mathrm{~kg}$. Cada piquete contou com 11 cordeiros-teste. Foi utilizada uma área adicional de azevém para manter os animais reguladores nos períodos em que estes não eram utilizados nas unidades experimentais. O período de utilização da pastagem foi de 19/08/99 a 11/11/99 totalizando 88 dias.

Semanalmente, media-se a altura da pastagem com o auxílio de um bastão graduado ("sward stick") em 100 pontos por piquete. Para manter as alturas pretendidas, utilizou-se um número variável de animais através da técnica da taxa de lotação variável descrita por Mott \& Lucas (1952), em pastejo contínuo.

Para a determinação das variáveis morfogênicas e estruturais utilizou-se a técnica de "perfilhos marcados", cuja metodologia é descrita em detalhes por Carrère et al. (1997). Em cada piquete marcou-se 50 perfilhos com fio de telefone colorido distribuídos ao longo de transectas. Em cada transecta foram marcados 10 perfilhos distanciados $50 \mathrm{~cm}$ entre si, deixando $5 \mathrm{~m}$ de distância entre as estacas das extremidades. A distribuição das transectas nos piquetes pretendeu representar toda a variabilidade possível dos mesmos, evitando-se áreas próximas às cercas. A cada avaliação observaram-se o comprimento e número de lâminas foliares maduras (com lígula visível) e em crescimento, além da sua condição (em senescência ou não e intacta ou desfolhada). No caso das folhas desfolhadas, o topo da lâmina era marcado com uma pequena incisão longitudinal, de forma que fosse possível detectar novas desfolhações. As folhas completamente expandidas foram medidas a partir de sua lígula, enquanto que as folhas em crescimento foram medidas a partir da penúltima lígula visível, conforme Davies (1993). Para as folhas em senescência era registrado o comprimento da parte verde e o comprimento da parte senescente. Medidas de altura de bainha também foram realizadas a partir do nível do solo até a lígula da última folha completamente expandida. Foram realizados dois ciclos de observações, em dois períodos distintos, sendo o primeiro do dia 12/08/99 a 15/09/99 e o segundo do dia 02 a 20/10/99, com cinco observações em cada ciclo, sendo que cada observação era realizada em intervalos de 3-4 dias. Após o primeiro ciclo, o processo de marcação das unidades vegetativas foi refeito para integrar novos indivíduos, visando manter a representatividade da população. Avaliou-se a lâmina verde total (LVT) por perfilho, que representa a soma dos comprimentos de lâmina verde das folhas do perfilho (intacta ou desfolhada) por dia de amostragem, expressa em $\mathrm{cm}$. A taxa de elongação foliar (TEF) foi obtida, para cada intervalo de dias de observação, pela diferença entre os comprimentos das lâminas verdes em expansão, tanto em lâminas intactas como nas desfolhadas. É expressa em $\mathrm{cm} /{ }^{\circ} \mathrm{C}$ através da divisão do valor obtido pela soma térmica (somatório das temperaturas médias diárias) entre os dias avaliados. No primeiro ciclo, o filocrono (F) e a taxa de surgimento de folhas (TSF) foram determinados por meio de regressão linear

R. Bras. Zootec., v.32, n.4, p.814-820, 2003 
entre o número de folhas produzidas e a soma térmica do período e, também, foram estimados a partir das seguintes fórmulas: $\mathrm{F}=\mathrm{CFLF} /(\mathrm{a} . \mathrm{TEF})$, sendo "CFLF" o comprimento final da lâmina foliar e "a" o número de folhas em expansão crescendo simultaneamente no mesmo perfilho (Lemaire \& Agnusdei, 1999). Ambos são expressos em graus-dia, o qual representa a energia que está a disposição da planta a cada dia (Nabinger, 1997). A taxa de surgimento de folhas representa o inverso do filocrono $(\mathrm{TSF}=1 / \mathrm{F})$. Não havendo diferença entre as duas formas de cálculo, optou-se pela segunda metodologia para obtermos o $\mathrm{F}$ e a TSF do ciclo seguinte. O tempo de vida das folhas (TVF) completamente expandidas foi estimado através da relação entre o filocrono e o número máximo de folhas vivas por perfilho (NMFV) (TVF= NMFV/F), enquanto o tempo de duração da elongação (TDE) foi calculado pela relação $\mathrm{TDE}=\mathrm{a} . \mathrm{F}$.

A determinação da densidade populacional de perfilhos foi realizada por contagem em cinco amostras de $0,125 \mathrm{~m}^{2}$ cada por piquete, cortadas rente ao solo, em duas datas distintas, a saber: 05/08/99 e 11/11/99.

Os dados foram analisados considerando a média dos cinqüenta perfilhos marcados de cada piquete como uma repetição. Foi realizada análise de regressão e correlação entre as variáveis morfogênicas e estruturais com as alturas reais obtidas na pastagem por intermédio do aplicativo SAS (Freud \& Littel, 1986).

\section{Resultados e Discussão}

Os ciclos de avaliação ocorreram em duas fases do experimento. A primeira fase iniciou-se com a entrada dos animais na pastagem (19/08/99), quando esta apresentava altura média geral de $25 \mathrm{~cm}$, até a sua estabilização nas alturas pretendidas, fato ocorrido por volta do dia 15/09/99. O ajuste de cargas inicial visando atingir as alturas pretendidas levou, portanto, 27 dias para atingir seu objetivo, mais do que o previsto. Os valores das características morfogênicas e estruturais para o primeiro ciclo de avaliação (Tabela 1) não apresentaram diferenças significativas, pois as alturas iniciais eram semelhantes em todos os piquetes. A segunda fase do experimento ocorreu quando as alturas pretendidas foram alcançadas. Os parâmetros referentes à caracterização da pastagem ao longo desse período de avaliação estão descritos na Tabela 2 (médias do período).

Durante o segundo ciclo de avaliação, a TEF apresentou uma regressão significativa $(\mathrm{P}<0,0007)$, aumentando linearmente com a altura (Figura 1), ficando os valores máximos encontrados em torno de $0,054 \mathrm{~cm} /{ }^{\circ} \mathrm{C}$. Resultados semelhantes foram verificados por Lemaire \& Agnusdei (1999) também com Lolium multiflorum. Esses autores observaram um aumento da TEF com a altura da pastagem, mas relatam que esse efeito da altura sobre a TEF ainda

Tabela 1 - Características morfogênicas e estruturais de Lolium multiflorum no período de 12/08/99 a 14/09/99 Table 1 - Morphogenetic and structural characteristics of Lolium multiflorum from 12/08/99 to 14/09/99

\begin{tabular}{|c|c|}
\hline $\begin{array}{l}\text { Características } \\
\text { Characteristics }\end{array}$ & $\begin{array}{c}\text { Valores médios observados e Desvio-padrão } \\
\text { Average values and Standard error }\end{array}$ \\
\hline Taxa de surgimento das folhas (folha/GD) & $0,0058 \pm 0,0011$ \\
\hline Leaf appearance rate (leaf/GD) & \\
\hline Filocrono (GD/folha) & $179,87 \pm 34,22$ \\
\hline Phyllochrone (GD/leaf) & \\
\hline Taxa de elongação foliar $\left(\mathrm{cm} /{ }^{\circ} \mathrm{C}\right)$ & $0,065 \pm 0,0059$ \\
\hline Leaf elongation rate $\left(\mathrm{cm} /{ }^{\circ} \mathrm{C}\right)$ & \\
\hline Tempo de vida das folhas expandidas (GD) & $392,82 \pm 131,66$ \\
\hline $\begin{array}{l}\text { Leaf lifespan (GD) } \\
\text { Tempo de duração da elongação (GD) }\end{array}$ & $301,16 \pm 27,69$ \\
\hline Duration of elongation of leaf (GD) & \\
\hline $\begin{array}{l}\text { Número de lâminas foliares verdes expandidas } \\
\text { Number of green expand leaf lamina }\end{array}$ & $2,16 \pm 0,35$ \\
\hline $\begin{array}{l}\text { Número de lâminas foliares em elongação } \\
\text { Number of leaf lamina in elongation }\end{array}$ & $1,7 \pm 0,31$ \\
\hline $\begin{array}{l}\text { Comprimento da lâmina foliar verde expandida }(\mathrm{cm}) \\
\text { Lenght o green leaf lamina }(\mathrm{cm})\end{array}$ & $19,3 \pm 1,8$ \\
\hline Lâmina verde total $(\mathrm{cm})$ & $49,2 \pm 5,07$ \\
\hline $\begin{array}{l}\text { Total green lamina }(\mathrm{cm}) \\
\left.\text { Densidade populacional de perfilhos (perfilhos } / \mathrm{m}^{2}\right) \\
\text { Tiller population density }\left(\text { tillers } / \mathrm{m}^{2}\right)\end{array}$ & $2823,73 \pm 349,9$ \\
\hline
\end{tabular}




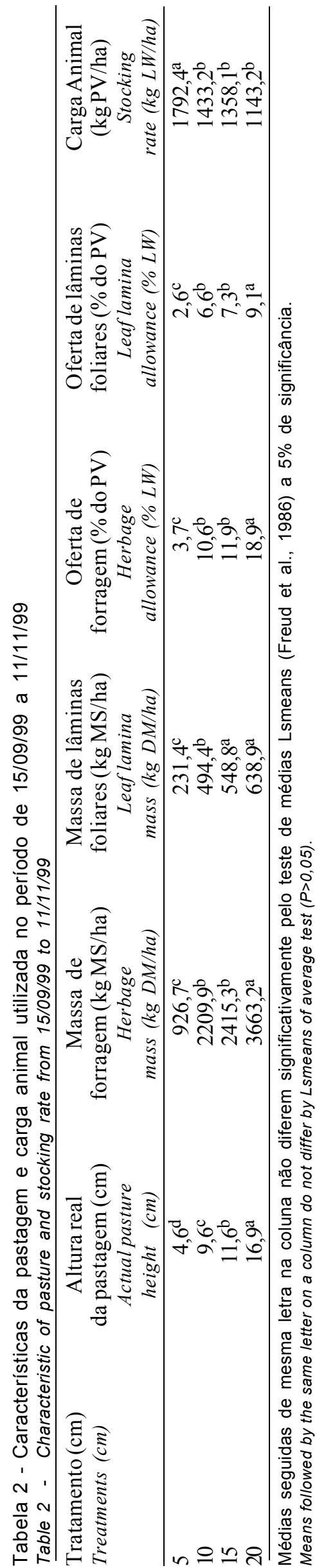

não está claramente explicado. Entretanto, admite-se que fatores como o comprimento da folha verde, tamanho do perfilho e o processo de remobilização de $\mathrm{N}$, podem contribuir para explicar o efeito acima reportado (Marriot et al., 1999). Dessa forma, esse aumento da TEF com a altura pode ter ocorrido em razão da maior massa de forragem e material senescente nesses tratamentos, o que proporciona uma maior remobilização de $\mathrm{N}$. A remobilização de $\mathrm{N}$ das folhas mais velhas para as folhas que estão em elongação é um processo que acompanha a senescência foliar (Lemaire \& Chapman, 1996). Segundo Bircham \& Hodgson (1983), em situações de pastejo, o aumento na densidade de animais irá gerar uma diminuição linear no fluxo de senescência, como resultado do aumento da probabilidade de desfolhação de folhas individuais, diminuindo, assim, a reciclagem de $\mathrm{N}$ na parte aérea das plantas, ocasionando uma maior dependência pela disponibilidade de $\mathrm{N}$ do solo ou reservas nas raízes. Lemaire \& Gastal (1997) destacam que a capacidade de remobilização de $\mathrm{N}$ entre diferentes órgãos da planta ocorre em uma velocidade superior à taxa de absorção pelas raízes.

Outro fator importante a ser considerado é o efeito dos diferentes padrões de desfolhação sobre a TEF. Nabinger (1997) destacou que a TEF praticamente não é afetada pela desfolhação que remova duas ou três folhas por perfilho, mas é diminuída em cerca de 15 a $20 \%$ quando todas as folhas de um perfilho são removidas. No presente trabalho, em alturas próximas a $5 \mathrm{~cm}$, durante o segundo ciclo, cerca de $83,16 \%$ do comprimento dos tecidos de lâminas foliares foi removido a cada desfolha. Uma

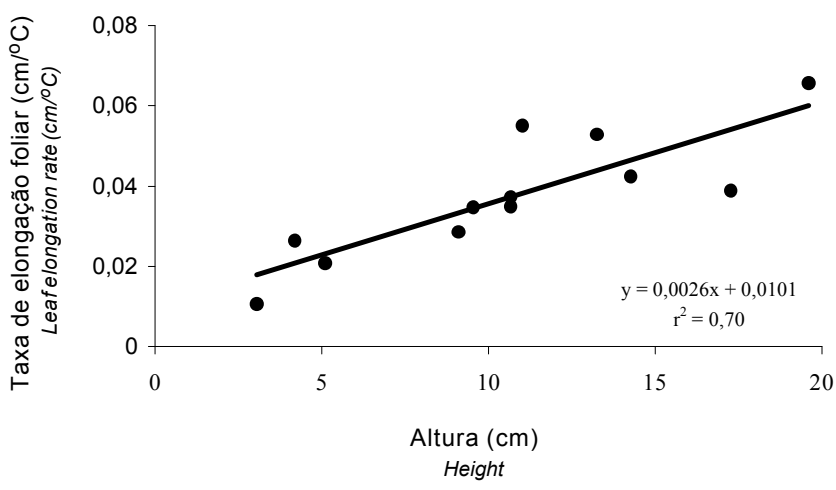

Figura 1 - Relação entre a altura da pastagem e a taxa de elongação foliar.

Figure1 - Relation between sward height and leaf elongation rate.

R. Bras. Zootec., v.32, n.4, p.814-820, 2003 
correlação significativa e negativa entre a intensidade de desfolha por lâmina e a TEF foi observada $(r=-0,84$; $\mathrm{P}<0,0006$ ). Schnynder et al. (2000) afirmaram que desfolhações freqüentes levam a uma forte redução da TEF, o que estaria associado com o decréscimo na taxa de produção celular e duração da expansão celular.

Independentemente da altura da pastagem, diferenças $(\mathrm{P}<0,0001)$ ocorreram entre folhas desfolhadas e intactas. A TEF média das folhas intactas foi igual a $0,057 \mathrm{~cm} /{ }^{\circ} \mathrm{C}$, enquanto que para as folhas, após o processo de desfolha, a taxa foi reduzida para 0,017 $\mathrm{cm} /{ }^{\circ} \mathrm{C}$, observando-se, portanto, uma redução de $70 \%$.

A TSF não foi afetada pelas diferentes alturas de manejo da pastagem. O intervalo médio entre o aparecimento de duas folhas sucessivas foi de $6 \times 10^{-3} \pm 3 \times 10^{-3}$ folhas/Graus-Dia (GD), correspondente a um filocrono de $166 \pm 60 \mathrm{GD}$. Esse resultado é semelhante ao encontrado por Lemaire \& Agnusdei (1999), cujos valores de filocrono não apresentaram diferenças quanto às alturas de manejo numa pastagem de azevém, sendo sua média igual a 170 GD, mas se diferenciam dos encontrados por Viégas (1998). Esse último autor encontrou valores mais baixos (para a mesma espécie), entre 120 e 150 $\mathrm{GD} /$ folha, para o filocrono. Essas diferenças podem ter ocorrido porque as condições ambientais, no presente experimento, não foram controladas e talvez não tenham sido potencializadas. No trabalho desenvolvido por Viégas (1998), todos os fatores possíveis de variação (água e nutrientes) foram controlados, de modo que a cultura tivesse condições de expressar todo o seu potencial produtivo dentro das limitações de radiação solar e temperatura predominantes.

Da mesma forma que a TSF, o tempo de vida das folhas completamente expandidas não foi significativamente afetado pela altura da pastagem. O TVF médio observado foi de 358,7 \pm 191 GD. Considerando que a média das temperaturas médias diárias ocorridas no período foi de $16,2^{\circ} \mathrm{C}$, o tempo de vida de uma folha completamente expandida foi de, aproximadamente, 22 dias. Por outro lado, o TDE $(\mathrm{P}<0,0131)$ diminuiu linearmente com a altura (Figura 2), apresentando valores oscilando entre 216 GD na maior altura e 362 GD na menor altura. Vários autores citam o efeito inverso dessa característica como, por exemplo, no trabalho desenvolvido por Duru \& Ducrocq (2000) com Dactylis glomerata, no qual o TDE aumentou com a altura da pastagem devido ao aumento no comprimento da bainha. Talvez, um dos motivos para o comportamento observado do TDE tenha sido uma resposta da planta em nível trófico, ou seja, nas maiores alturas, com a manutenção de uma maior área foliar, a maior interceptação de luz determinou aumento na oferta de $\mathrm{C}$, elevando, assim, a velocidade de expansão foliar, já que altas taxas de elongação foliar foram observadas nesses tratamentos. A este efeito soma-se o efeito antes discutido de uma provável maior disponibilidade de $\mathrm{N}$ através da reciclagem interna da planta, a partir das folhas em senescência. Assim, mesmo sendo o comprimento de bainha maior nos tratamentos de maior altura, pois foi possível observar um aumento equivalente a $0,6 \mathrm{~cm}$ de comprimento de bainha para cada centímetro de altura da pastagem, o conseqüente aumento no TDE não foi verificado. A maior TEF observada nesses tratamentos pode ter sido suficiente para compensar a distância de bainha a ser percorrida, resultando em menor TDE.

No que concerne às variáveis estruturais da pastagem, tamanhos diferentes de lâminas foram encontrados quando a altura foi alterada. As maiores alturas de pasto resultaram em folhas mais extensas que as demais $(\mathrm{P}<0,0020)$ (Figura 3). Utilizando a regressão obtida, verifica-se que as folhas produzidas na pastagem mantida a $20 \mathrm{~cm}$ apresentaram um comprimento médio de $12,1 \mathrm{~cm}$, enquanto que na pastagem mantida a $5 \mathrm{~cm}$ as mesmas folhas têm seu tamanho final restrito a $6,8 \mathrm{~cm}$, ou seja, uma redução de cerca de $44 \%$. Os fatores determinantes do tamanho da folha são a TEF e a TSF (Lemaire \& Chapman, 1996). Devido à modificação ocorrida no balanço entre essas duas características (TEF aumentou sig-

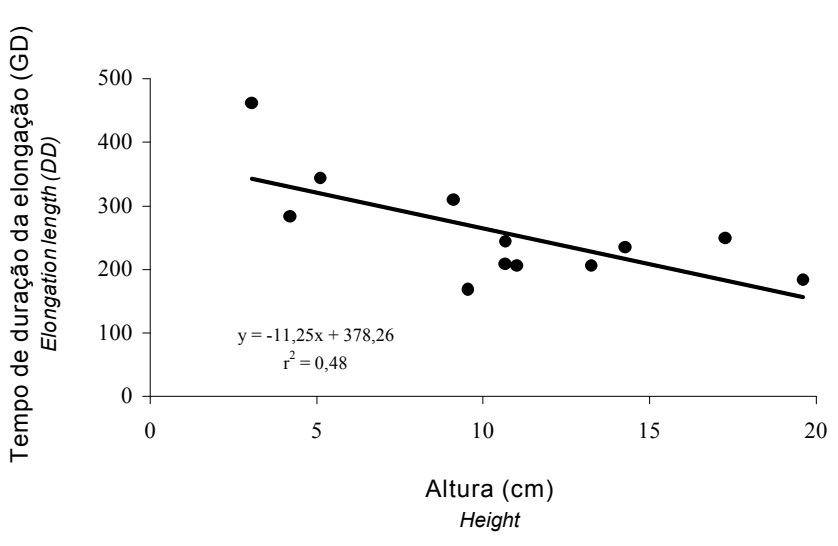

Figura 2 - Relação entre a altura da pastagem e o tempo de duração da elongação.

Figure 2 - Relation between sward height and elongation length. 
nificativamente com a altura), o comprimento da lâmina também foi alterado. A análise de correlação mostrou uma associação positiva entre as variáveis TEF e comprimento da lâmina foliar inteira $(\mathrm{r}=0,90 \mathrm{e}$ $\mathrm{P}<0,0001)$. A altura da bainha é outro fator importante a ser considerado, pois quanto maior o seu comprimento, maior será a fase de multiplicação celular, mais tempo a folha que está em expansão ficará protegida pela bainha da luz direta (Davies et al., 1989) e, conseqüentemente, maior será a TEF e o tamanho da lâmina (Duru \& Ducroq, 2000).

O número médio de folhas vivas por perfilho foi de 2,0 $\pm 0,5$ folhas expandidas e 1,7 $\pm 0,6$ folhas em expansão, totalizando $3,7 \pm 0,2$ folhas, número este bastante semelhante ao encontrado para azevém perene, como relatado por Marriot et al. (1999). A densidade populacional de perfilhos não foi afetada significativamente pelos tratamentos $(4614,41 \pm 1257$ perfilhos $/ \mathrm{m}^{2}$ ), talvez em razão das medidas terem sido realizadas no período pós-indução floral, o que não permitiria tempo suficiente para as plantas expressarem a sua plasticidade fenotípica no que se refere a essa variável. Porém, algumas respostas de adaptação das plantas ao pastejo (plasticidade fenotípica) puderam ser observadas. É o caso da diminuição do comprimento da bainha (intacta) com a diminuição da altura da pastagem. Essa redução no tamanho dos perfilhos individuais foi uma resposta plástica às freqüentes e severas desfolhações ocorridas nesses tratamentos. Essa habilidade da espécie em alterar suas características morfológicas, como o comprimento da bainha, em resposta ao regime de desfolhação é de grande importância, pois irá influenciar na acessibilidade desses tecidos ao pastejo ani-

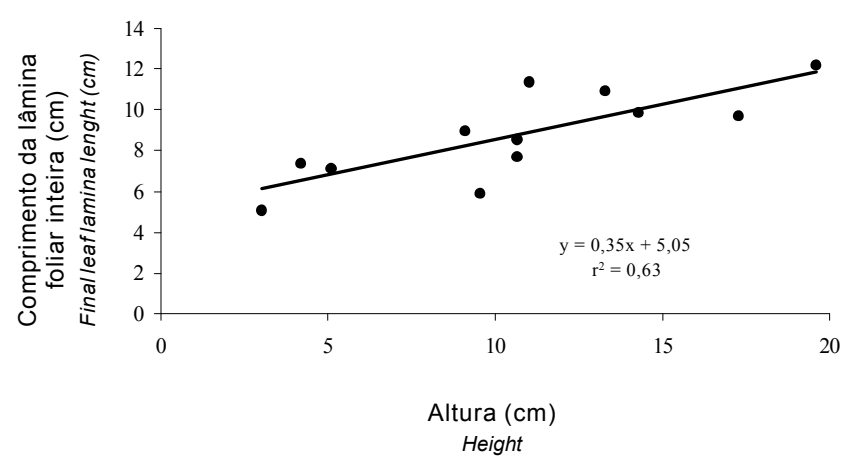

Figura 3 - Relação entre a altura da pastagem e o comprimento da lâmina foliar inteira.

Figure 3 - Relation between sward height and the final leaf lamina lenght. mal (Lemaire \& Chapman, 1996). No entanto, como demostrado na Figura 4, nota-se que a bainha não diminui ou cresce proporcionalmente com a altura da pastagem (ver em relação à linha de eqüiprobabilidade (1:1)). À medida que se aumenta a altura da pastagem maior é a distância entre a bainha e o topo do dossel, proporcionando a existência de uma maior camada pastejável (profundidade de pastejo).

Nas maiores alturas, os perfilhos também apresentaram maior LVT $(\mathrm{P}<0,0001)$, devido, fundamentalmente, ao maior comprimento e à menor intensidade de desfolhação de cada uma de suas lâminas, uma vez que o número de folhas vivas por perfilho não sofreu alteração. O aumento da LVT com a altura (Figura 5) proporcionou uma maior área foliar nesses tratamentos, determinando uma maior interceptação da radiação e fotossíntese disponibilizando, assim, uma maior oferta de $\mathrm{C}$ e, conseqüentemente, maior taxa de acúmulo de biomassa. Conforme os resultados aqui observados, o aumento na altura da pastagem de cinco para $20 \mathrm{~cm}$ eqüivale a aumentar o comprimento total de folhas verdes por $\mathrm{m}^{2}$ de 32.575 para $102.477 \mathrm{~cm}$. Considerando-se que a relação comprimento-largura se mantenha estável nos diferentes tratamentos, significará um aumento da área de interceptação luminosa de cerca de três vezes.

A utilização de pastagens consiste essencialmente na remoção de lâminas. Estas desempenham um papel importante na ecologia de sistemas pastoris, uma vez que produzem os assimilados necessários para o crescimento e manutenção da planta, além de servir como fonte de alimento para os organismos heterotróficos, incluindo os ruminantes. A habilidade de manter a produção de folhas em face as freqüentes

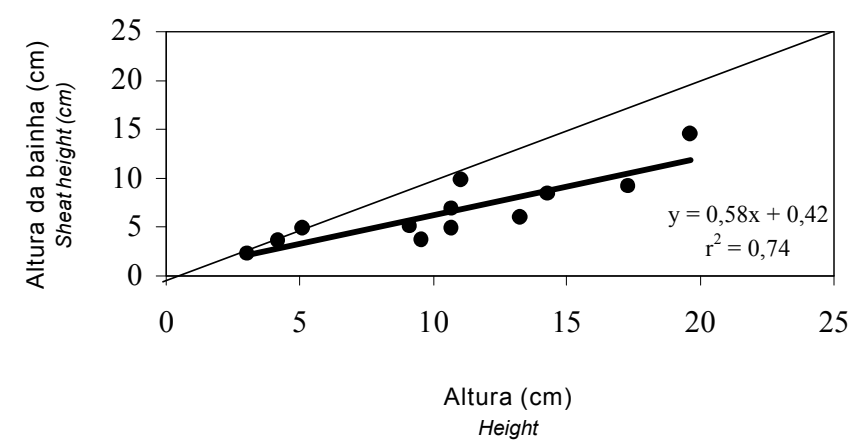

Figura 4 - Relação entre a altura da pastagem e a altura da bainha.

Figure 4 - Relation between sward height and the sheat height.

R. Bras. Zootec., v.32, n.4, p.814-820, 2003 


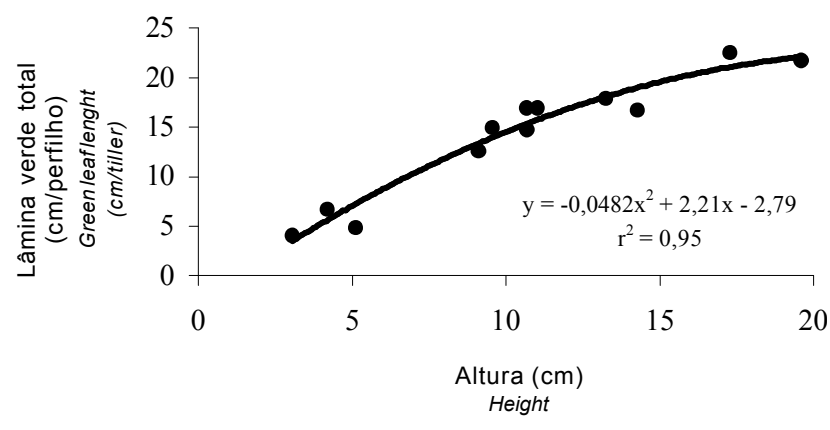

Figura 5 - Relação entre a altura da pastagem e o comprimento de lâmina verde por perfilho.

Figure 5 - Realtionship between sward height and the green leaf lenght.

e severas desfolhações torna-se essencial para a produção sustentável das pastagens e sobrevivência das plantas pastejadas. Dessa forma, analisando os resultados apresentados nesta pesquisa, observou-se que a altura em que a pastagem mantida afeta os mecanismos básicos que estão diretamente envolvidos no processo de crescimento das lâminas foliares e, portanto, na produtividade desse ecossistema forrageiro.

\section{Conclusões}

A altura em que a pastagem de azevém anual é mantida, no presente caso, não alterou a densidade populacional de perfilhos, a taxa de surgimento de folhas, o número de folhas vivas por perfilho ou a duração de vida das mesmas. No entanto, a medida em que a altura da pastagem foi aumentada, observou-se uma maior taxa de elongação foliar, menor tempo de duração da elongação da folha e maior tamanho final das mesmas, que resultou em maior comprimento de folhas verdes por perfilho. Severas intensidades de desfolha provocam alterações na morfogênese e estrutura da pastagem, diminuindo o aproveitamento dos recursos do meio para produção de forragem.

\section{Agradecimento}

À CAPES, pela concessão da bolsa; à FAPERGS, pelo financiamento do trabalho, e à empresa Cerro Coroado, pela cessão dos animais e pelo apoio.

\section{Literatura Citada}

CARRÈRE, P.; LOUAUlT, F.; SOUSSANA, J.F. Tissue turnover within grass-clover mixed swards grazed by sheep. Methodology for calculating growth, senescence and intake fluxes. Journal of Applied Ecology, v.34, p.333-348, 1997.

BIRCHAM, J.S., HODGSON, J. The influence of sward condition on rates of herbage growth and senescence in mixed swards under continuous stoching management. Grass and Forage Scince, v.38, p.323-331, 1983.

DAVIES, A. Tissue turnover in the sward. In: DAVIES, A.; BAKER, R.D.; GRANT, S.A. et al. (Eds.). Sward measurement handbook. London: British Grassland Society, 1993. p.183-216.

DAVIES, D.A.; FOTHERGILL, M.; JONES, D. Frequency of stocking rate required on contrasting upland perennial ruegrass pastures continuously grazed to a sward height criterium from May to July. Grass and Forage Science, v.44, p.213-221, 1989.

DURU, M., DUCROCQ, H. Growth and senescence of the successive grass leaves on a tiller ontogenic development and effect of temperature. Annals of Botany, v.85, p.635-643, 2000.

EMBRAPA, Centro Nacional de Pesquisa de Solos. Sistema Brasileiro de Classificação de Solos. Brasília: EMBRAPA/ CNPS, 1999. 412p. il. (Documentos, 5).

FREUD, R.J.; LITTELL, R.C. SAS system for regression. Cary: SAS Institute Inc., 1986, 164p.

FREUD, R.J.; LITTEL, R.C.; SPECTOR, P.C. SAS SYSTEM FOR Linear Models. Cary: SAS Institute Inc., 1986. 210p.

LEMAIRE, G.; AGNUSDEI, M. Leaf tissue turn-over and efficieny of herbage utilisation. In: INTERNATIONAL SYMPOSIUM "GRASSLAND ECOPHSIOLOGY AND GRAZING ECOLOGY”, 1999, Curitiba. Anais... Universidade Federal de Curitiba, 1999. p.165-186.

LEMAIRE, G.; CHAPMAN. D. Tissue flows in grazed plant communities. In: HODGSON, J.; ILLIUS, A.W. (Eds.) The ecology and management of grazing systems. Wallingford: CAB International, 1996. p.3-36.

LEMAIRE, G.; GASTAL, F.N uptake and distribuition in plant canopies. In: LEMAIRE, G. (Ed.) Diagnosis of nitrogen status in crop. Heidelberg: Springer - Verlag, 1997. p. 3-43.

MARRIOT, C.A.; BARTHRAM, G.T.; BOLTON, G.R. Seasonal dynamics of leaf extension and losses to senescence and herbivory in extensively managed sown ryegrass-white clover swards. Journal of Agricultural Science, v.132, p.77-89, 1999.

MOTT, G.O., LUCAS, H.L. The design, conduct and interpretation of grazing trials on cultivated and improved pastures. In: INTERNATIONAL GRASSLAND CONGRESS, 6., 1952, State College. Proceedings... State College: Pensylvania State College Press, 1952. p.1380-1385.

NABINGER, C. Eficiência do uso de pastagens: disponibilidade e perdas de forragem. In: SIMPÓSIO SOBRE MANEJO DA PASTAGEM, 14., 1997, Piracicaba. Anais... Piracicaba: Fundação de Estudos Agrários Luiz de Queiroz, 1997. p.213-251.

SCHNYDER, H. et al. An integrated view of C and N uses in leaf growth zones of defoliated grasses. In: INTERNATIONAL SYMPOSIUM "GRASSLAND ECOPHSIOLOGY AND GRAZING ECOLOGY”, 1999, Curitiba. Anais... Universidade Federal de Curitiba, 2000. p.75-94.

VIÉGAS, J. Análise do desenvolvimento foliar e ajuste de um modelo de previsão do rendimento potencial de matéria seca de azevém anual (Lolium multiflorum Lam.). Porto Alegre: Universidade Federal do Rio Grande do Sul, 1998. 166p. Tese (Doutorado em Zootecnia) - Universidade Federal do Rio Grande do Sul, Porto Alegre, 1998.

Recebido em: 14/05/02 Aceito em: 18/12/02

R. Bras. Zootec., v.32, n.4, p.814-820, 2003 